\title{
Mitochondrial DNA lineages of Italian Giara and Sarcidano horses
}

\author{
L. Morelli ${ }^{\dagger}$, A. Useli ${ }^{1}$, D. Sanna ${ }^{1}$, M. Barbato ${ }^{1,2}$, D. Contu ${ }^{3}$, M. Pala ${ }^{4,5}$, \\ M. Cancedda ${ }^{6}$ and P. Francalacci ${ }^{1}$ \\ ${ }^{1}$ Dipartimento di Scienze della Natura e del Territorio, \\ Unità di Zoologia Archeozoologia e Genetica, Università di Sassari, \\ Sassari, Italy \\ ${ }^{2}$ Cardiff School of Biosciences, Cardiff University, Cardiff, UK \\ ${ }^{3}$ Laboratorio di Immunogenetica, Ospedale Microcitemico, \\ Cagliari, Italy \\ ${ }^{4}$ Dipartimento di Biologia e Biotecnologie "L. Spallanzani” Università di Pavia, \\ Pavia, Italy \\ ${ }^{5}$ School of Applied Sciences, University of Huddersfield, Queensgate, \\ Huddersfield, UK \\ ${ }^{6}$ Dipartimento di Medicina Veterinaria, Università di Sassari, Sassari, Italy \\ ${ }^{\dagger}$ This paper is dedicated to the memory of Laura Morelli who prematurely \\ passed away before the publication. \\ Corresponding author: A. Useli \\ E-mail: auseli@uniss.it
}

Genet. Mol. Res. 13 (4): 8241-8257 (2014)

Received December 18, 2012

Accepted June 14, 2013

Published October 20, 2014

DOI http://dx.doi.org/10.4238/2014.October.20.1

\begin{abstract}
Giara and Sarcidano are 2 of the 15 extant native Italian horse breeds with limited dispersal capability that originated from a larger number of individuals. The 2 breeds live in two distinct isolated locations on the island of Sardinia. To determine the genetic structure and evolutionary history of these 2 Sardinian breeds, the first hypervariable segment of the mitochondrial DNA (mtDNA) was sequenced and analyzed in 40 Giara and Sarcidano horses and compared with publicly available mtDNA data from 43 Old World breeds. Four
\end{abstract}


different analyses, including genetic distance, analysis of molecular variance, haplotype sharing, and clustering methods, were used to study the genetic relationships between the Sardinian and other horse breeds. The analyses yielded similar results, and the $F_{\mathrm{ST}}$ values indicated that a high percentage of the total genetic variation was explained by between-breed differences. Consistent with their distinct phenotypes and geographic isolation, the two Sardinian breeds were shown to consist of 2 distinct gene pools that had no gene flow between them. Giara horses were clearly separated from the other breeds examined and showed traces of ancient separation from horses of other breeds that share the same mitochondrial lineage. On the other hand, the data from the Sarcidano horses fit well with variation among breeds from the Iberian Peninsula and North-West Europe: genetic relationships among Sarcidano and the other breeds are consistent with the documented history of this breed.

Key words: Mitochondrial DNA; Giara horse; Sarcidano horse; Haplogroup attribution; Domestication

\section{INTRODUCTION}

Island environments enable the persistence of relic varieties of species or breeds. Among the 15 horse breeds officially recognized by the Italian Registry of Autochthonous Equine Breeds, 2 breeds, which are inbred and phenotypically distinctive, are from the island of Sardinia (Figure 1).

The Giara horses take their name by the basalt plateau in the central/south region of Sardinia where they live in the wild. The Giara plateau extends over an area of $45 \mathrm{~km}^{2}$ at an altitude of about 500-600 $\mathrm{m}$ above sea level. The steep mountain slopes limit connections with the surrounding valleys and prevent migration of the horses. The average height of Giara horse approaches that of a pony, but it is considered a miniature horse. The bioecological features of this population make it a rich livestock heritage to safeguard and a guarantee of protection for the natural environment where it lives (Gratani, 1980).

The Sarcidano horses are concentrated on a single farm in Laconi (in central-western Sardinia). The history of how the breed was introduced onto the island is controversial and mostly unknown; nonofficial records suggest a descent from the ancient Spanish horse, an ancestor of the Andalusian breed.

At the end of the 18th century, Cetti (1774) described the presence on Sardinia of 3 different types of horses, the "selvaticus" (wild), the "vulgar" (common or ordinary), and the "di razza" (thoroughbred) horse. Cetti's description of the height and temperament of "selvaticus" is consistent with the descriptions of the present-day Giara horse. On the other hand, the "vulgar" Cetti's horse description fits well with that of the present population of the Sarcidano breed in terms of character, phenotype, and work attitude. At present, there are 481 registered Giara and 108 Sarcidano horses (http://www.anagrafeequidi.it/index.php?id=217).

The aim of this study was to shed light on the genetic structure of the Giara and Sarcidano horses in a global context to depict their genetic relationships with other present-day 
breeds. To achieve this goal, we compared a sample of the 2 Sardinian breeds with a large number of horses genotyped to date. For this comparison, we selected a 247-bp long internal portion of the hyper-variable region segment I (HVS-I) of the control displacement loop (d-loop) of mitochondrial DNA (mtDNA). This choice was made for three reasons: 1) sequence variation in these mtDNA regions is solely generated by the sequential accumulation of new mutations along radiating maternal lineages; 2) maternal lineages are presumably more stable because of the practice to move stallions for reproduction and breed improvement, so mtDNA sequences should present breed-specific motifs that relate our samples to a geographical origin; and 3) a large number of d-loop sequences from many horse breeds is available in GenBank.

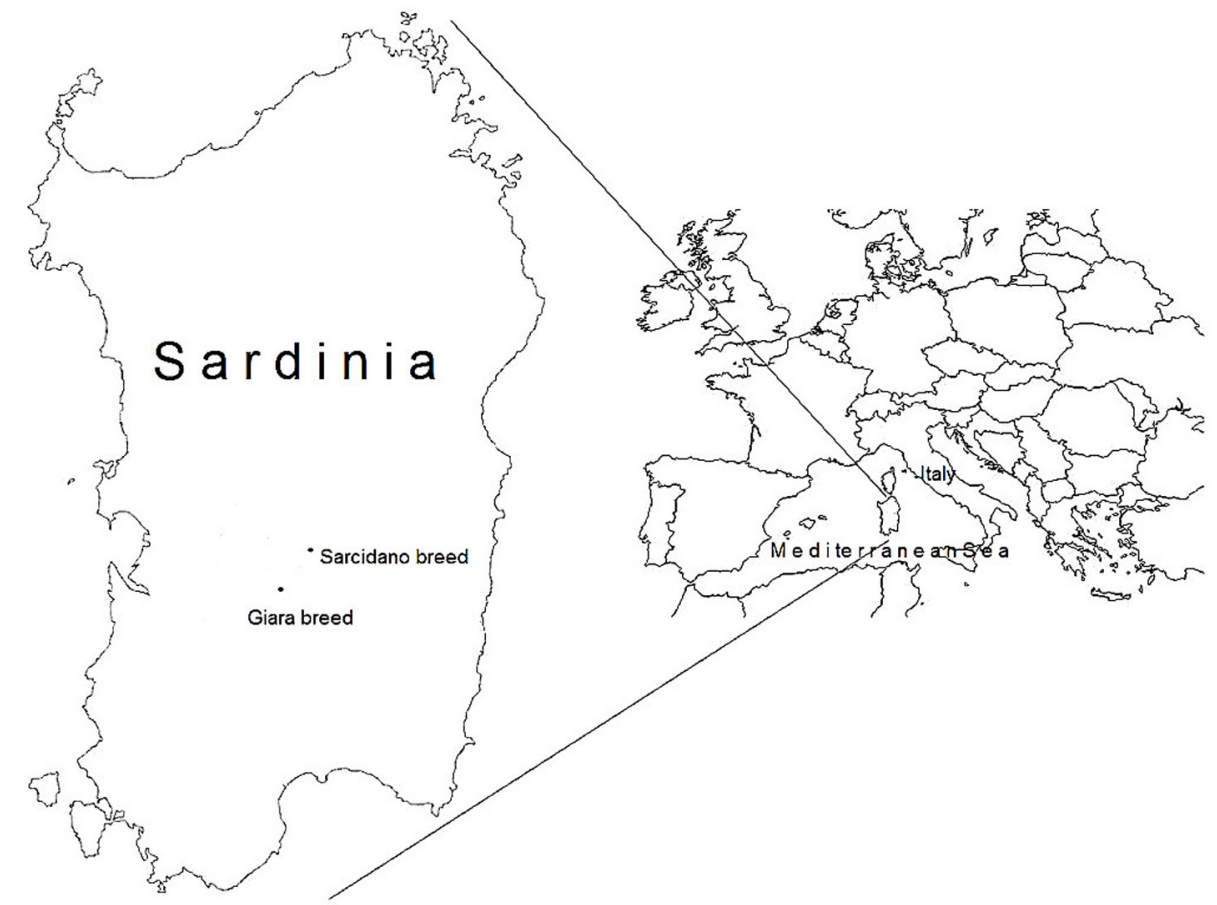

Figure 1. Range of distribution in Giara and Sarcidano breeds.

To date, only limited data (Cozzi et al., 2004; Achilli et al., 2012) on mtDNA variation in Sardinian horse breeds are available. A comparison of a limited number of Sardinian horses with other Italian breeds suggests a reduced relationship with the other Italian populations (Cozzi et al., 2004).

\section{MATERIAL AND METHODS}

\section{Materials}

Using standard procedures, total DNA was extracted from peripheral blood samples of 24 horses of the Giara breed and 16 horses of the Sarcidano breed. The Giara and Sarcidano 
horses had been bred in semiferal conditions, and animals were randomly selected by capture.

The sequences produced in this study were pooled with 5 sequences from Giara (GRH1-5; GenBank accessions AY462426-AY462430) and 5 from Sarcidano (SRH1-5; AY462451-AY462455) breeds previously reported by Cozzi et al. (2004), and with 2 additional HVS-I sequences identified in the complete mtDNA genome sequences (Gia01, JN398411 and Gia02, JN398407) reported by Achilli et al. (2012). The final sample set used in the analyses was obtained from 31 Giara and 21 Sarcidano horses.

In addition, all the 150 complete mtDNA genome sequences available from literature [NC_001640 (Xu and Arnason, 1994); EF597512-14 (Xu et al., 2007); AP012267-70 (Goto et al., 2011); EU939445 (Jiang et al., 2011); HQ439441-500 (Lippold et al., 2011); and JN398377-457 (Achilli et al., 2012)] were used to obtain more reliable and informative HVS-I patterns of sites defining haplogroups.

Finally, we produced a dataset of typical regional breeds by selecting 1192 HVS-I horse sequences from the literature for which frequency population data were available and which were reported for at least 15 individuals. Taking into account the haplotype frequencies, we obtained 1232 HVS-I samples belonging to 45 breeds (including Giara and Sarcidano) representing 6 geographic Old World macroareas: the Iberian Peninsula $(\mathrm{N}=220)$, Central Europe $(\mathrm{N}=400)$, Northwest Africa $(\mathrm{N}=40)$, the Arabian Peninsula $(\mathrm{N}=70)$, Central Eurasia $(\mathrm{N}=113)$, and the Far East $(\mathrm{N}=389)$.

\section{Methods}

The HVS-I of the d-loop region was amplified by the polymerase chain reaction (PCR) using two primers from a published horse sequence (GenBank accession No. X79547): forward 5'-AACGTTTCCTCCCAAGGACT-3' and reverse 5'-GTAGTTGGGAGGGTTGCTGA-3' (Ishida et al., 1994; Xu and Arnason, 1994). The amplicon obtained was a 397-bp fragment included between the tRNA ${ }^{\text {Pro }}$ gene and the large central conserved sequence block from nucleotide position 15382-15778. The PCR products were purified by using ExoSAP-IT (USB Corporation) and sequenced using the BigDye Terminator Kit (Applied Biosystems) on an ABI PRISM 377 DNA Sequencer equipped with the Sequencing Analysis and Sequence Navigator programs (Applied Biosystems). Sequence alignments were performed with the BioEdit 7.0.5.2 software (Hall, 1999).

Intra- and interpopulation level methods were conducted with the Arlequin 3.5. software (Excoffier et al., 2005) (http://cmpg.unibe.ch/software/arlequin3): intrapopulation level variation was estimated with both standard (gene diversity; Nei, 1987) and molecular indices as pairwise differences (Tajima, 1993) and nucleotide diversity (Tajima, 1983; Nei, 1987). Population genetic structure was obtained by hierarchical analysis of the total variance subdivided in percentage of variance within the breeds, among breeds within groups and among groups by using molecular analysis of variance (AMOVA) (Excoffier et al., 1992) taking into account the number of mutations between molecular haplotypes. In both cases, the F-statistic was set at a significance level of 0.05 , obtained by 10,000 permutation tests. The matrix of interpopulation pairwise distances (Tajima, 1993, Arlequin software) was summarized in two dimensions by using multidimensional scaling (MDS) analysis as implemented by the STATISTICA '99 software (StatSoft, Tulsa, OK, USA) and plotted on an MS Excel graphic. 
Haplogroups attribution was performed following the nomenclature rules of Achilli et al. (2012). To increase the power of imputation of the HVS-I sequences, we pooled together all the available horse complete mtDNA genome sequences. Polymorphic sites occurring among the total of 150 sequences were exported as an Excel spreadsheet and the haplotypes were organized in haplogroups following a hierarchical and parsimonious order, and the haplogroup name was assigned to the unclassified data. Three of them were eliminated because their polymorphisms were not consistent with phylogeny as previously observed by Lippold et al. (2011) and Achilli et al. (2012). The mutational pattern was dissected in order to define the following variables:

- variation associated univocally with the haplogroup; this variation is due to the most informative mutations since they are present in all of the haplotypes of the same haplogroup and absent in other haplogroups;

- variation associated univocally with the super-haplogroup; this variation is due to mutations that allow allocation to a unique clade represented by individuals that share the same mutation because it is ancestral for all the haplogroups that compose it;

- variation due to mutations occurring in a unique haplogroup but not in all of the haplotypes of this haplogroup;

- variation due to informative mutations in the allelic association; reversion.

- variation due to poorly informative mutations that are the result of recurrence or

The haplotypic pattern of the HVS-I region was extracted and a probabilistic algorithm defining haplogroup attribution was generated when only the HVS-I sequence was available. Haplotype variation and haplotype sharing into the haplogroups were evaluated by clustering in the Network program 5.0.0, and default parameters were used for obtaining the median-joining network trees (Bandelt et al., 1999). A weight of 0 were assigned to mutations classified as recurrent. In addition, mismatch distribution of the number of pairwise differences between haplotypes among haplogroups and associated demographic parameters including Harpending's raggedness index $(r)$, Tajima's $D(D)$, and Fu's $\left(F_{\mathrm{S}}\right)$ statistics were calculated using the Arlequin 3.5 software.

\section{RESULTS}

\section{Diversity indices}

The 52 sequences obtained from the Sardinian horses consisted of 29 different haplotypes on the segment ranging from nucleotide position 15494 to 15740 (Table 1).

We calculated the diversity indices from 43 native breeds scattered in the Old World (see Table 2, for details).

We compared diversity indices from Old World breeds to those obtained from the Sardinian horses: both the haplotype diversity values of the Giara $(0.847 \pm 0.053)$ and Sarcidano $(0.905 \pm 0.047)$ breeds were higher than the average estimates for the other 43 breeds, but only the Sarcidano breed was above the median of the distribution (Table 3). Other molecular diversity indices that were also considered (see Table 3) showed that the heterogeneity of the Sarcidano sample (mean number of pairwise differences, $6.738 \pm 3.309$ and nucleotide diversity, $0.027 \pm 0.015$ ) was comparable with the highest values reported for the other breeds, whereas Giara horses showed a lower molecular diversity (mean number of pairwise differences, 3.933 \pm 2.025 and nucleotide diversity, $0.016 \pm 0.009)$. 


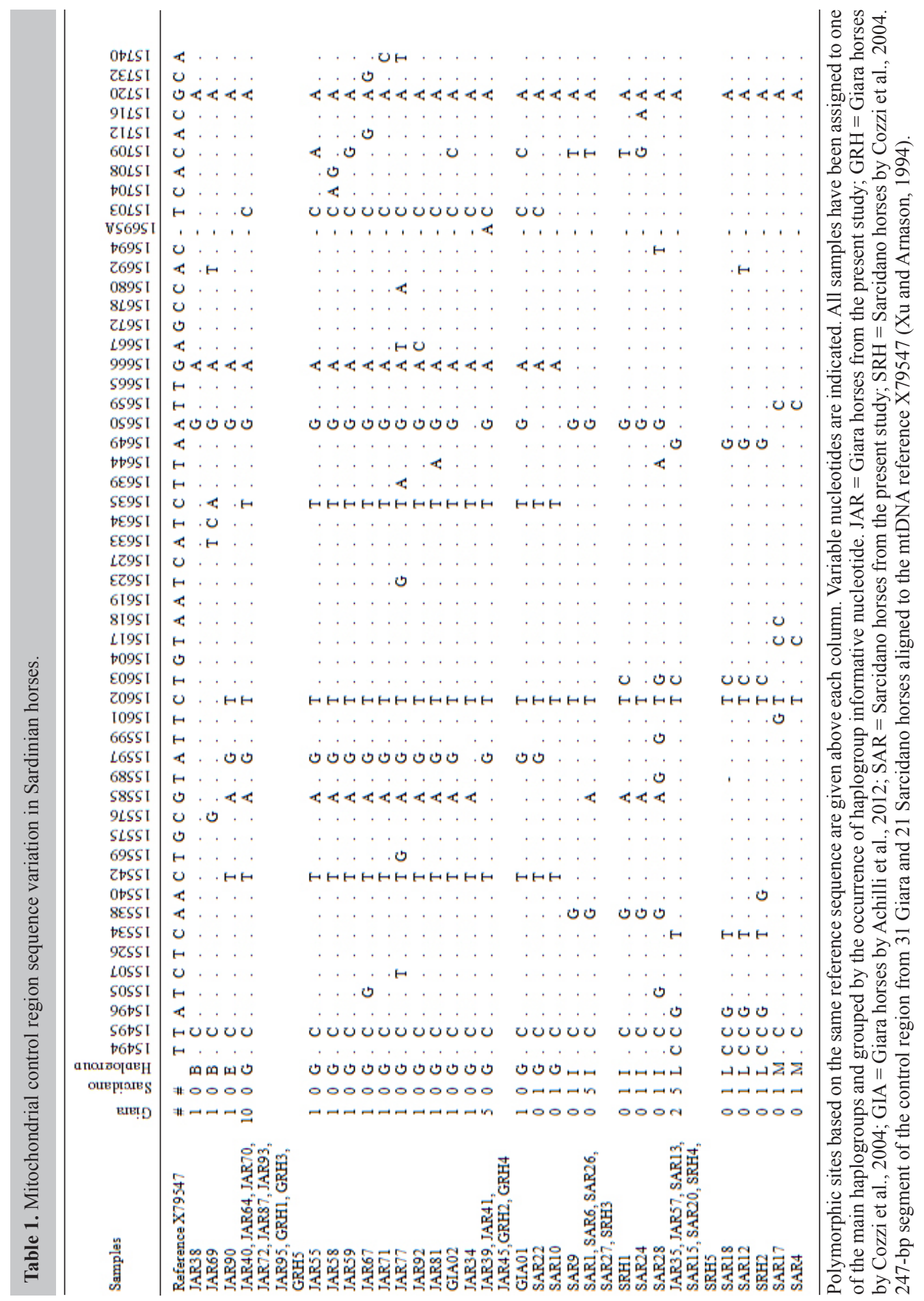


Table 2. Forty-five Old World native breeds.

\begin{tabular}{|c|c|c|c|}
\hline Macroarea & Breed & Code & References and GenBank accessions \\
\hline North-western Africa & Barb & BAR & Jansen et al., 2002; EF686021-45 \\
\hline Iberian Peninsula & $\begin{array}{l}\text { Andalusian } \\
\text { Asturcòn } \\
\text { Caballo de Corro } \\
\text { Garrano } \\
\text { Jaca Navarra } \\
\text { Losino } \\
\text { Lusitano } \\
\text { Marismeno } \\
\text { Pottoka } \\
\text { Sorraia }\end{array}$ & $\begin{array}{l}\text { AND } \\
\text { AST } \\
\text { CCO } \\
\text { GAR } \\
\text { JAN } \\
\text { LOS } \\
\text { LUS } \\
\text { MAR } \\
\text { POT } \\
\text { SOR }\end{array}$ & $\begin{array}{l}\text { Mirol et al., 2002; Jansen et al., 2002; Royo et al., 2005; Luís et al., 2006a } \\
\text { Mirol et al., 2002; Royo et al., 2005; HQ827083-90 } \\
\text { Royo et al., 2005; HQ827099-103 } \\
\text { Royo et al., 2005; Luís et al., 2006a; AY246231-4 } \\
\text { HQ827104-HQ827118 } \\
\text { Mirol et al., 2002; Royo et al., 2005; HQ827119-29 } \\
\text { Jansen et al., 2002; Luís et al., 2006a; AY246242-7 } \\
\text { Royo et al., 2005; HQ827136-45 } \\
\text { Mirol et al., 2002; Royo et al., 2005; HQ827156-61 } \\
\text { Jansen et al., 2002; Luís et al., 2006a,b; HQ827162-3; AY246259-65 }\end{array}$ \\
\hline Central Europe & $\begin{array}{l}\text { Exmoor } \\
\text { Fell } \\
\text { Giara } \\
\text { Irish Draught } \\
\text { Kerry Bog Pony } \\
\text { Percheron } \\
\text { Rhineland Heavy Draft } \\
\text { Sanfratellano } \\
\text { Sarcidano } \\
\text { Scottish Highland } \\
\text { Senner } \\
\text { Shetland } \\
\text { Sicilian Indigenous } \\
\text { Sicilian Oriental Purebred }\end{array}$ & $\begin{array}{l}\text { EXM } \\
\text { FEL } \\
\text { GIA } \\
\text { IRD } \\
\text { KEB } \\
\text { PER } \\
\text { RHD } \\
\text { SAN } \\
\text { SAR } \\
\text { SCH } \\
\text { SEN } \\
\text { SHE } \\
\text { SII } \\
\text { SOP }\end{array}$ & $\begin{array}{l}\text { Jansen et al., 2002; AY246219-24 } \\
\text { Bower et al., 2011 } \\
\text { Present study; Cozzi et al., 2004; Achilli et al., } 2012 \\
\text { McGahern et al., 2006a } \\
\text { McGahern et al., 2006a } \\
\text { Kakoi et al., } 2007 \\
\text { Jansen et al., } 2002 \\
\text { Zuccaro et al., 2009; Guastella et al., } 2011 \\
\text { Present study; Cozzi et al., 2004 } \\
\text { Jansen et al., 2002; Bower et al., } 2010 \\
\text { Jansen et al., 2002 } \\
\text { Hill et al., 2002; Jansen et al., 2002; Bower et al., 2011; AY246253-8 } \\
\text { Zuccaro et al., 2009; Guastella et al., } 2011 \\
\text { Zuccaro et al., 2009; Guastella et al., } 2011\end{array}$ \\
\hline Arabian Peninsula & Arabian & ARA & Bowling et al., 2000; Mirol et al., 2002; Jansen et al., 2002; AY246180-5 \\
\hline Central Eurasia & $\begin{array}{l}\text { Akhal-Teke } \\
\text { Anatolian } \\
\text { Kazahk } \\
\text { Mesenskay } \\
\text { Vyayskaya } \\
\text { Yakut }\end{array}$ & $\begin{array}{l}\text { AKT } \\
\text { ANA } \\
\text { KAZ } \\
\text { MES } \\
\text { VYA } \\
\text { YAK }\end{array}$ & $\begin{array}{l}\text { McGahern et al., 2006b; AY246174-9 } \\
\text { Hill et al., } 2002 \\
\text { Lei et al., } 2009 \\
\text { McGahern et al., 2006b } \\
\text { McGahern et al., 2006b } \\
\text { McGahern et al., 2006b }\end{array}$ \\
\hline Far East & $\begin{array}{l}\text { Baise } \\
\text { Cheju } \\
\text { Debao } \\
\text { Guanzhong } \\
\text { Guizhou } \\
\text { Mongolian } \\
\text { NingQiang } \\
\text { Tibetan } \\
\text { Hokkaido } \\
\text { Misaki } \\
\text { Taishu } \\
\text { Tokara } \\
\text { Yonaguni }\end{array}$ & $\begin{array}{l}\text { BAI } \\
\text { CHE } \\
\text { DEB } \\
\text { GUA } \\
\text { GUI } \\
\text { MON } \\
\text { NIN } \\
\text { TIB } \\
\text { HOK } \\
\text { MIS } \\
\text { TAI } \\
\text { TOK } \\
\text { YON }\end{array}$ & $\begin{array}{l}\text { GQ203128-GQ203143; GQ222059-60 } \\
\text { Yang et al., 2002; AY246201-8 } \\
\text { EU826536; FJ392562-80; GQ203125-7 } \\
\text { Lei et al., 2009 } \\
\text { Lei et al., 2009 } \\
\text { Jansen et al., 2002; McGahern et al., 2006b; Kakoi et al., } 2007 \\
\text { Lei et al., 2009 } \\
\text { DQ986464-79 } \\
\text { Kakoi et al., } 2007 \\
\text { Kakoi et al., } 2007 \\
\text { Kakoi et al., } 2007 \\
\text { Kakoi et al., } 2007 \\
\text { Kakoi et al., } 2007\end{array}$ \\
\hline
\end{tabular}

\section{Genetic structure}

We used AMOVA on the basis of the pairwise difference distance method (Excoffier et al., 1992; Weir, 1996) to determine the genetic structure of the group composed by the Giara and the Sarcidano populations. A relevant and significant percentage of interpopulation variation (45.1\%) was detected when compared with the intrapopulation variation $(54.9 \%$; $\mathrm{P}<$ $10^{-5}$ ). Therefore, taking into account that in all of the 45 worldwide diffused breeds analyzed, $25 \%\left(\mathrm{P}<10^{-5}\right)$ of the total variation is allocated to the among-breeds source, we can confidently predict the presence of a genetic barrier between the two Sardinian breeds. The same value 
was obtained after grouping into macrogeographical areas as reported in column 1 of Table 2, and no variance was attributable to the differences between groups. Just a small, but significant, amount of variation was related to the east (Arabian Peninsula, Central Eurasia, Far East) and west (Northwest Africa, Iberian Peninsula, Central Europe) groupings $(2.89 \% ; \mathrm{P}=0.01)$.

\begin{tabular}{|c|c|c|c|c|c|c|c|c|c|c|}
\hline \multirow[t]{2}{*}{ Breed } & \multirow[t]{2}{*}{ Individuals } & \multirow[t]{2}{*}{ Haplotypes } & \multirow{2}{*}{$\begin{array}{l}\text { Polymorphic } \\
\text { sites }\end{array}$} & \multirow{2}{*}{$\begin{array}{c}\text { Sum of } \\
\text { square frequencies }\end{array}$} & \multicolumn{2}{|c|}{ Haplotype diversity } & \multicolumn{2}{|c|}{ Pairwise differences } & \multicolumn{2}{|c|}{ Nucleotide diversity } \\
\hline & & & & & $\mathrm{h}$ & SD & MNPD & SD & $\pi$ & SD \\
\hline BAR & 40 & 14 & 23 & 0.165 & 0.856 & 0.040 & 4.659 & 2.332 & 0.019 & 0.010 \\
\hline AND & 30 & 15 & 22 & 0.104 & 0.926 & 0.026 & 5.400 & 2.677 & 0.022 & 0.012 \\
\hline AST & 21 & 9 & 21 & 0.134 & 0.910 & 0.035 & 7.381 & 3.596 & 0.030 & 0.016 \\
\hline $\mathrm{CCO}$ & 19 & 4 & 10 & 0.357 & 0.678 & 0.088 & 3.719 & 1.965 & 0.015 & 0.009 \\
\hline GAR & 18 & 14 & 20 & 0.080 & 0.974 & 0.025 & 6.327 & 3.147 & 0.026 & 0.014 \\
\hline JAN & 15 & 14 & 22 & 0.076 & 0.991 & 0.028 & 6.381 & 3.203 & 0.026 & 0.015 \\
\hline LOS & 23 & 15 & 24 & 0.081 & 0.961 & 0.022 & 6.719 & 3.288 & 0.027 & 0.015 \\
\hline LUS & 21 & 10 & 15 & 0.147 & 0.895 & 0.039 & 5.943 & 2.953 & 0.024 & 0.013 \\
\hline MAR & 22 & 9 & 15 & 0.169 & 0.870 & 0.044 & 5.931 & 2.942 & 0.024 & 0.013 \\
\hline POT & 21 & 18 & 26 & 0.066 & 0.981 & 0.023 & 6.600 & 3.247 & 0.027 & 0.015 \\
\hline SOR & 30 & 5 & 12 & 0.422 & 0.598 & 0.059 & 2.232 & 1.265 & 0.009 & 0.006 \\
\hline EXM & 18 & 6 & 20 & 0.247 & 0.797 & 0.066 & 5.209 & 2.644 & 0.021 & 0.012 \\
\hline FEL & 17 & 8 & 19 & 0.177 & 0.875 & 0.053 & 5.500 & 2.783 & 0.022 & 0.013 \\
\hline GIA & 31 & 15 & 31 & 0.180 & 0.847 & 0.053 & 3.933 & 2.025 & 0.016 & 0.009 \\
\hline IRD & 59 & 28 & 31 & 0.070 & 0.946 & 0.017 & 6.373 & 3.063 & 0.026 & 0.014 \\
\hline KEB & 39 & 17 & 26 & 0.090 & 0.934 & 0.020 & 5.614 & 2.753 & 0.023 & 0.012 \\
\hline PER & 15 & 3 & 10 & 0.662 & 0.362 & 0.145 & 2.800 & 1.566 & 0.011 & 0.007 \\
\hline RHD & 24 & 15 & 24 & 0.118 & 0.920 & 0.040 & 6.754 & 3.298 & 0.027 & 0.015 \\
\hline SAN & 20 & 11 & 20 & 0.130 & 0.916 & 0.041 & 6.295 & 3.117 & 0.025 & 0.014 \\
\hline SAR & 21 & 13 & 26 & 0.138 & 0.905 & 0.047 & 6.738 & 3.309 & 0.027 & 0.015 \\
\hline $\mathrm{SCH}$ & 31 & 16 & 26 & 0.086 & 0.944 & 0.021 & 6.185 & 3.021 & 0.025 & 0.014 \\
\hline SEN & 19 & 2 & 1 & 0.900 & 0.105 & 0.092 & 0.105 & 0.183 & 0.000 & 0.001 \\
\hline SHE & 66 & 15 & 26 & 0.134 & 0.880 & 0.023 & 6.441 & 3.088 & 0.026 & 0.014 \\
\hline SII & 20 & 13 & 30 & 0.120 & 0.926 & 0.043 & 7.132 & 3.492 & 0.029 & 0.016 \\
\hline SOP & 20 & 1 & 0 & 1.000 & 0.000 & 0.000 & 0.000 & 0.000 & 0.000 & 0.000 \\
\hline ARA & 70 & 37 & 37 & 0.042 & 0.972 & 0.007 & 6.231 & 2.995 & 0.025 & 0.013 \\
\hline AKT & 24 & 14 & 27 & 0.108 & 0.931 & 0.033 & 6.859 & 3.345 & 0.028 & 0.015 \\
\hline ANA & 15 & 11 & 17 & 0.102 & 0.962 & 0.034 & 5.333 & 2.727 & 0.022 & 0.012 \\
\hline KAZ & 18 & 16 & 31 & 0.068 & 0.987 & 0.023 & 6.131 & 3.059 & 0.025 & 0.014 \\
\hline MES & 18 & 11 & 26 & 0.136 & 0.915 & 0.050 & 5.549 & 2.797 & 0.022 & 0.013 \\
\hline VYA & 18 & 10 & 17 & 0.124 & 0.928 & 0.037 & 5.216 & 2.646 & 0.021 & 0.012 \\
\hline YAK & 20 & 12 & 20 & 0.105 & 0.942 & 0.030 & 6.021 & 2.995 & 0.024 & 0.014 \\
\hline BAI & 18 & 16 & 37 & 0.068 & 0.987 & 0.023 & 7.974 & 3.888 & 0.032 & 0.018 \\
\hline CHE & 73 & 15 & 24 & 0.114 & 0.899 & 0.017 & 4.974 & 2.447 & 0.020 & 0.011 \\
\hline DEB & 23 & 15 & 31 & 0.093 & 0.949 & 0.028 & 6.727 & 3.292 & 0.027 & 0.015 \\
\hline GUA & 27 & 10 & 20 & 0.180 & 0.852 & 0.039 & 5.556 & 2.754 & 0.022 & 0.012 \\
\hline GUI & 62 & 27 & 33 & 0.082 & 0.933 & 0.019 & 5.799 & 2.812 & 0.023 & 0.013 \\
\hline MON & 35 & 17 & 27 & 0.084 & 0.943 & 0.019 & 6.424 & 3.116 & 0.026 & 0.014 \\
\hline NIN & 27 & 16 & 26 & 0.092 & 0.943 & 0.027 & 5.880 & 2.898 & 0.024 & 0.013 \\
\hline TIB & 16 & 14 & 22 & 0.078 & 0.983 & 0.028 & 6.742 & 3.355 & 0.027 & 0.015 \\
\hline HOK & 28 & 3 & 13 & 0.865 & 0.140 & 0.087 & 1.325 & 0.850 & 0.005 & 0.004 \\
\hline MIS & 26 & 3 & 10 & 0.731 & 0.280 & 0.107 & 1.563 & 0.963 & 0.006 & 0.004 \\
\hline TAI & 16 & 3 & 14 & 0.594 & 0.433 & 0.138 & 3.600 & 1.927 & 0.015 & 0.009 \\
\hline TOK & 19 & 1 & 0 & 1.000 & 0.000 & 0.000 & 0.000 & 0.000 & 0.000 & 0.000 \\
\hline YON & 19 & 2 & 1 & 0.501 & 0.526 & 0.040 & 0.526 & 0.460 & 0.002 & 0.002 \\
\hline
\end{tabular}

$\mathrm{MNPD}=$ mean number of pairwise differences.

The relationship between the different breeds was inferred by estimating the pairwise differences between breeds and interpolating the data into an MDS graphic (Figure 2).

This graph shows a large presence of outliers representing low variability (Figure 2A and see also Table 3 ) and clustering of the majority of breeds having higher variation (Figure 

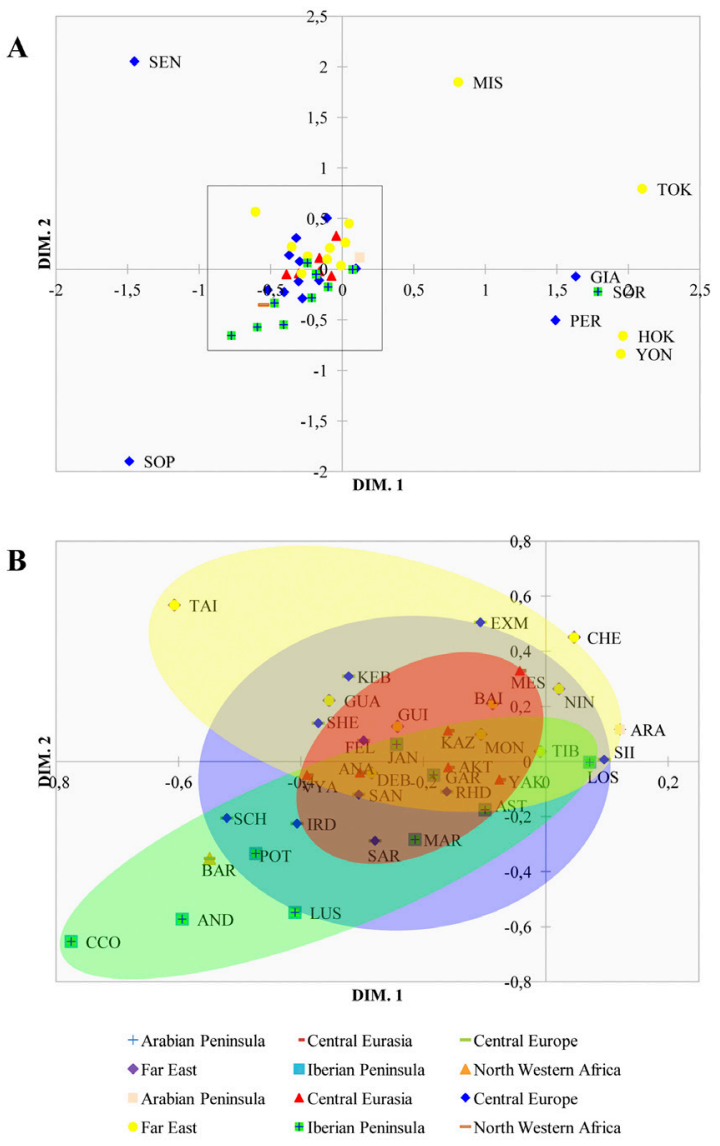

Figure 2. Multidimensional scaling (MDS) plot computed from the matrix of the pairwise differences of the mitochondrial HVS-I sequences. Each symbol represents the breeds from the 6 geographic Old World macroareas. Breed codes are as in Table 2. In the section A of the graph only breeds outside the main cluster are indicated. The breeds enclosed in the square are highlighted in the section B. Colors of the spots: green - Iberian Peninsula, blue - Central Europe, red - Central Eurasia, yellow - Far East. D-star: Raw stress = 30.54; Alienation $=0.12 ;$ D-hat: Raw stress $=24.05 ;$ Stress $=0.11$.

2A and B enlarged). The Giara sample lies in an outlier position because of its low variability. In contrast, the Sarcidano sample is located in an area of generally high variability, included in the Western European group of breeds.

\section{Haplogroup assignment}

The phylogenetic analysis involving 147 complete mtDNA genome sequences reported from the literature allowed us to infer the HVS-I haplotype patterns and assign them to the 18 (A-R) haplogroups (Achilli et al., 2012) with better confidence. HVS-I was affected by variation that differed in the quality and degree of information (see Methods). The haplogroups D, F, H, I, L, M, N, Q, and R were defined by highly informative mutations linked univocally to their haplogroup (see Table 4). 


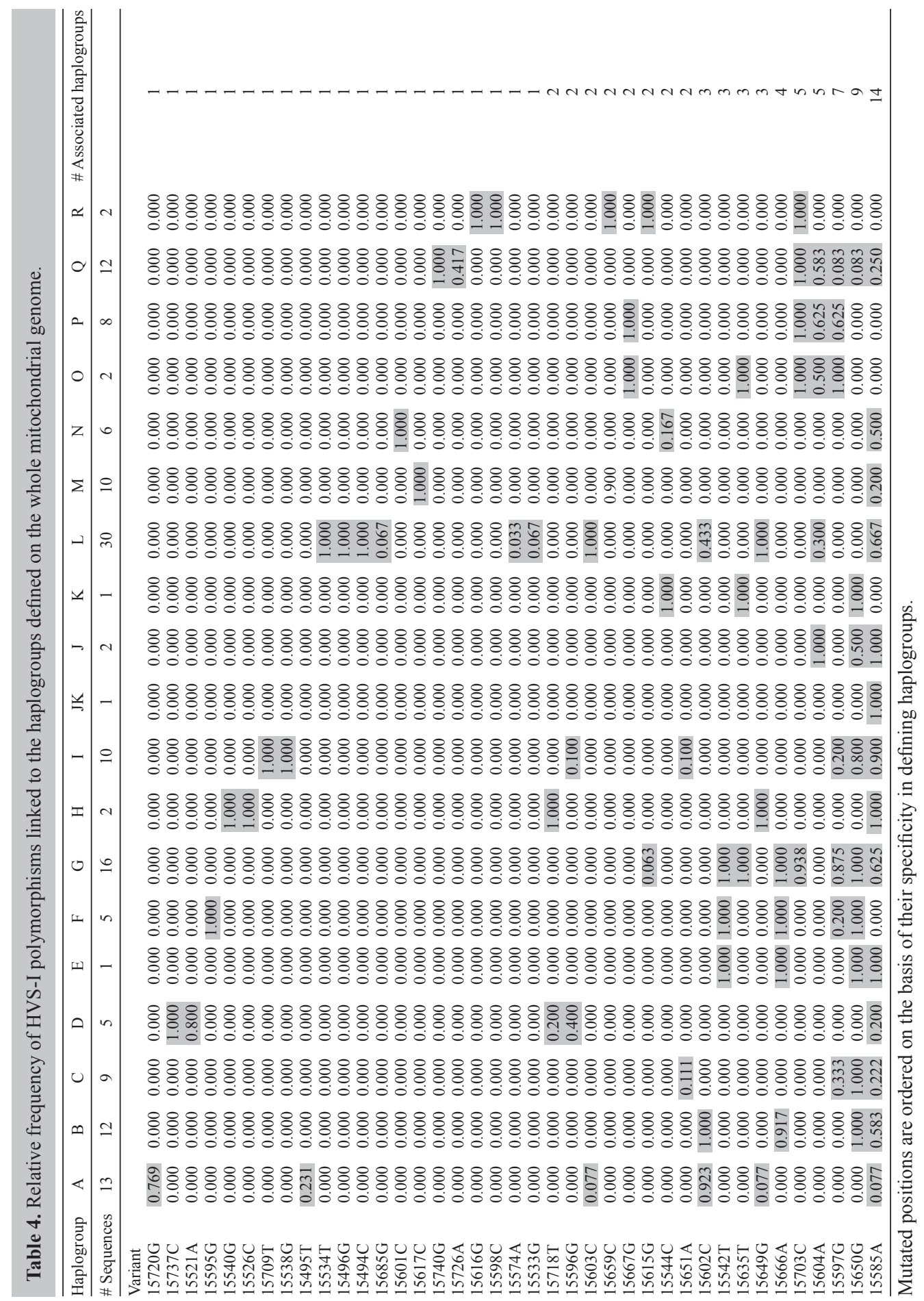


The EFG clade was defined by the $15542 \mathrm{~T}$ and $15666 \mathrm{~A}$ mutations. Haplogroup F was distinguished in its clade by the haplogroup F-specific mutation 15595G, whereas haplogroup $\mathrm{G}$ was characterized by its association with the $15635 \mathrm{~T}$ mutation. The clade OPQR was defined by the mutation 15703T, and the inside group OP was identified by the mutation $15667 \mathrm{G}$.

About $80 \%$ of the A haplotypes had the mutation $15720 \mathrm{G}, 20 \%$ of which showed an association between $15720 \mathrm{G}$ and $15495 \mathrm{G}$. Overall, the $20 \%$ of the A haplotypes had no diagnostic sites and the accuracy of their haplogroup attribution could only be confirmed when HVS-I-specific sites were available.

The B haplotypes were attributed on the basis of an allelic association/exclusion criterion in $90 \%$ of cases on the basis of the 15666 A mutation if this mutation was not associated with the $15542 \mathrm{~T}$ mutation typical of the EFG clade. However, $10 \%$ of the B sequences did not contain any diagnostic nucleotide site.

The haplogroup $\mathrm{C}$ and the JK clade, well defined by specific variants in the coding region, were associated with hypervariable mutations in HVS-I. For this reason, when these mutations were available, inference of haplogroup attribution was conducted by either a comparison or an exclusion criterion.

Following the algorithm shown in Table 4, we classified the HVS-I mtDNA of the 45 typical breeds. In total, 237 haplotypes were identified from the breed dataset and 229 were attributed to haplogroups. Eight haplotypes (3.4\%) were unambiguously attributable (Table S1). The polymorphism $15602 \mathrm{C}$ appeared to be phylogenetically recursive in the L lineage and was also observed in all A and B lineages; analogously, the 15585A, 15597G, 15604A, and 15650G mutations were not specifically associated with the haplogroups, and for this reason we attributed a null phylogenetic weight to these markers.

All of the HVS-I sequences of the Sardinian horses were assigned to corresponding haplogroups on the basis of univocal mutations and other sufficiently informative polymorphisms, so further sequencing or genotyping of specific diagnostic sites in the coding region was not required (see the haplogroup attribution in Table 1).

Twenty-six of 31 HVS-I sequences from the Giara breed belonged to the G haplogroup. In fact, this haplogroup was associated with the pattern 15542T, 15666A, 15650G, and $15635 \mathrm{G}$ in all of the 16 complete mtDNA sequences belonging to this haplogroup, and was more variable in the $15597 \mathrm{G}$ and $15703 \mathrm{C}$ variants. Overall, the $\mathrm{G}$ haplogroup represented $84 \%$ of the Giara maternal lineages.

The 21 Sarcidano sequences belonged mainly to haplogroups I (43\%) and L (38\%). Haplogroup L was defined by the HVS-I pattern 15494C, 15496G, 15534T, 15602C, 15603C, and $15649 \mathrm{G}$ present in 30 haplogroup $\mathrm{L}$ whole mtDNA genome sequences. On the other hand, the I haplogroup in the HVS-I of the 10 complete mtDNA genome sequences was defined by $15709 \mathrm{~T}$ and $15538 \mathrm{G}$.

Intrahaplogroup variation of the 3 main lineages found in the Giara and Sarcidano horses (haplogroups I, G, and L) was examined in all the available breed data by using the clustering method of the median-joining network. All of these maternal lineages produced a nascent star-like structure of the networks suggesting recent growth.

Haplogroup G (Figure 3) was poorly differentiated in eastern breeds, while a relevant number of subtypes were present in the breeds from Central Europe and the Iberian Peninsula, indicating differences in demographic growth between the eastern and western macroareas. In particular, the longest branches were often shared between samples from different breeds. Haplogroup $\mathrm{G}$ was the main haplogroup in the Giara horses. In this breed, the ancestral form 
of the haplogroup $\mathrm{G}$ evolved into several derivate haplotypes that are scarcely shared with other breeds. By contrast, haplogroup G was rare in the Sarcidano horses and its derivative lineages were shared with samples from the Iberian Peninsula.

The network of haplogroup I (Figure 3) showed a strong signal of population size expansion in breeds from north-western Europe and less differentiation in other macroareas. It was common in the Sarcidano maternal lineages where it was represented by derived and private lineages.

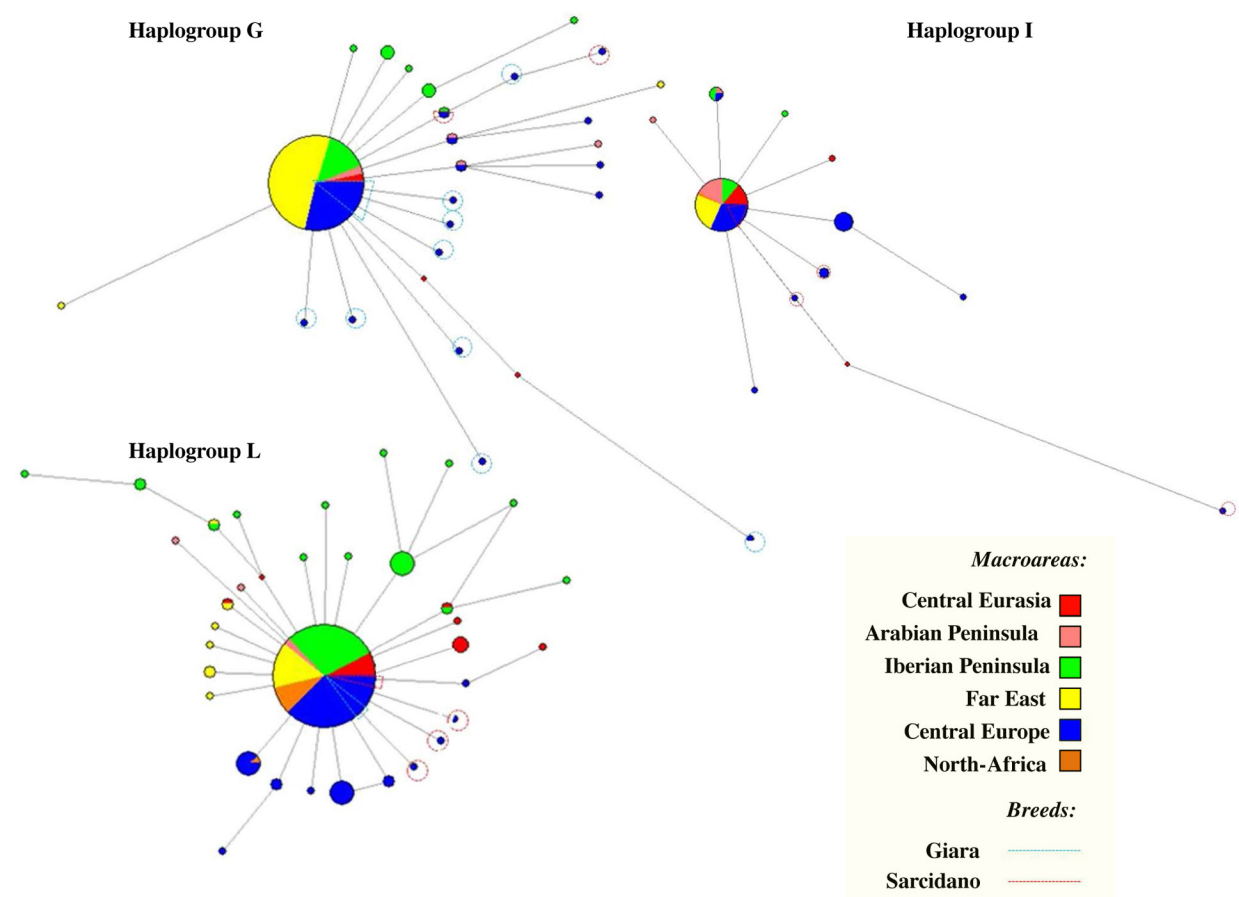

Figure 3. G, I and L intrahaplogroup variations analyzed by neighbor-joining networks.

The network of the haplotypes belonging to the haplogroup L (Figure 3) also showed a recent worldwide growth, but, unlike for haplogroups $\mathrm{G}$ and I, the expansion had been similar in eastern and western breeds, even if there were relatively fewer eastern $L$ lineages than western lineages. The location of major evolution was identified as the Iberian Peninsula, but the haplotype sharing of new lineages among macroareas and breeds was very low. The Sarcidano breed displayed emergence of 3 new haplotypes in the evolution of the haplogroup, whereas this was rarely observed in the Giara breed.

Mismatch distribution of the G, I, and L haplogroups in breeds from western and eastern Eurasia and from Sardinia indicated a recent expansion that seems to have occurred earlier in haplogroup $L$ than in the other 2 haplogroups, as indicated by a greater number of pairwise differences (Figure 4).

For the same reason, it is postulated that an earlier western Eurasian expansion took place in the haplogroups I and G. However, correlated $r, D$, and $F_{\mathrm{S}}$ statistics gave negative values not significantly different from 0 , indicating that rare alleles were not more frequent 
than expected from a null-neutral hypothesis in an equilibrium population. Moreover, pairwise differences did not fit well into an unimodal mismatch distribution model. This could be explained by a stationary population size or by very slow growth of the population.
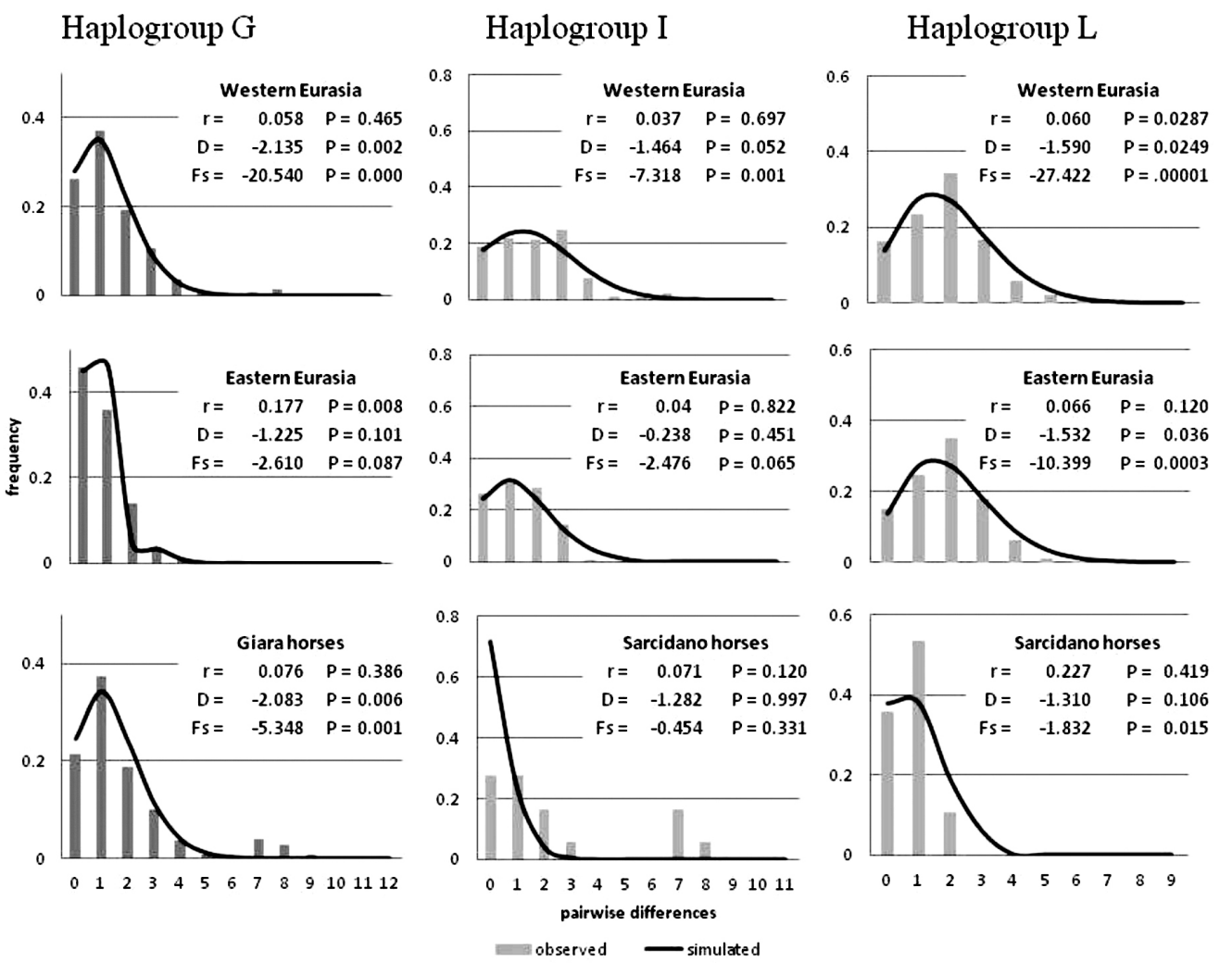

Figure 4. Intrahaplogroup variation analyzed by mismatch distribution analysis in Western and Eastern Eurasian breeds and in Sardinian breeds. Mismatch distributions were established for the haplogroups G, I, and L. Black lines represent the expected mismatch distribution of a stationary population. Histograms represent the observed mismatch distribution from segregating sites of the aligned sequences of HVS-I sequences in horse mtDNA.

\section{DISCUSSION}

The mtDNA genetic structure of the lineages observed in the domestic breeds can be used to infer their demographic and domestication history (Kavar and Dovc, 2008; Cieslak et al., 2010; Georgescu et al., 2011). To infer information about the demographic history and origin of the 2 Sardinian Giara and Sarcidano breeds from the genetic data, we compared these data with those from 43 typical breeds of the Old World.

The examined breeds displayed large molecular variation. These differences were not solely due to the total number of different haplotypes because a large amount of this molecular variation was due to the presence of different haplogroups in the same breed. The A-R haplogroups represent extant maternal lineages transmitted from a wild ancestral mare to the 
present-day mares: these haplogroups were defined on the complete mtDNA phylogeny as the cutoff of lineages that lived 10,000 years ago and whose haplogroups were transmitted during the process of domestication (Achilli et al., 2012). Therefore, the distinction between molecular variation that is produced before and after the formation of the present-day breeds is particularly relevant. Breeds that have more than 1 haplogroup show an ancestral variability that arose long before breed formation. In addition, as observed in the main lineage networks, the phylogeny of the single haplogroups showed a low degree of evolution: the molecular pattern of the HVS-I belonging to the same haplogroup was barely differentiated because only a limited number of new mutations had arisen in the ancestral haplotype. For this reason, breeds with a single haplogroup had lower molecular variation and were placed as outliers in the MDS graphics.

The emerging "star-like" phylogeny of the haplogroups indicated a population bottleneck followed by a small expansion in population size. In fact, the population size of breeds had remained relatively unchanged for a long time as indicated by the non-significant values of the $D$ and $F_{\mathrm{S}}$ statistics (Figure 4). The presence of a single (and usually frequent) ancestral haplotype shared by the majority of populations suggests founding of recent breeds from the same genetic pool.

As a consequence, all of the breeds that have maintained high haplogroup variability shared the same ancient variation and tended to cluster in the MDS graphic. Furthermore, the partition of the variability determined in AMOVA confirmed that only a small amount of variation was due to differences between breeds. For this reason, the different geographical areas of the breeds' origins tended to overlap (Figure 2A).

Nevertheless, we observed that the variability of breeds from the western European steppes, where, according to archeological records, the domestication originated (Outram et al., 2009), was central and entirely enclosed in the overall variability. Therefore, this area also represents the point of lineage radiation, and diversification in other geographical macroareas appears to be incipient and has not yet been completed.

In addition to suggesting a recent origin of the current breeds, our data also suggest that the homogeneity of the genetic pool may have been stable until recently when warrior peoples repeatedly migrated in several waves from the Central Eurasian steppes into Europe during the Middle Age. An east-west distribution of the variation was also apparent, probably generated from isolation by distance and weakly detected as significant by AMOVA when the breeds were merged into the two east and west Eurasia groups.

A genetic structuring occurred between the 2 Sardinian breeds (Figure 2) analyzed in this study, which were clearly separated and located in 2 different groups as determined by the mitochondrial lineage variation: the Sarcidano horse breed predominantly consisted of the haplogroups I and L, and other less frequent groups. This haplogroup variability, as mentioned above, is the result of molecular and haplotype diversity, which account for the presence of the Sarcidano among the most genetically variable breeds. The MDS analysis, which is based on genetic distances between breeds, effectively positioned the Sarcidano in the group with high variation, showing a greater affinity with the Iberian breeds as well as with those from north-western Europe, where the haplogroups L and I are highly represented. Haplogroup L is the most representative of the Iberian Peninsula, and Spanish influence in the Sardinia Island was strong until 1700. Moreover, none of the derivative Sarcidano horse L or I haplotypes is shared with the other continental breeds, suggesting that there was no recent gene flow from outside into the island. 
The Giara breed consisted almost exclusively of the haplogroup G, a very common worldwide haplogroup in horses and typical of many other outlier breeds. Unlike other breeds with little haplogroup variation, the Giara sample showed a significant molecular variation. Mismatch distribution in the Giara G haplogroup was comparable to those identified in the western eurasian population group. We therefore conclude that ancestors of the Giara horse in the past may have occupied an area that was larger than the one where they are found now, albeit always within the boundaries of the island. This interpretation is supported by historical records reporting the widespread presence in Sardinia of a horse described as "wild" that was phenotypically similar to the Giara horse (Cetti, 1774).

In conclusion, in this study we have first described the distribution of the current genetic diversity in typical breeds of horses and compared genetic differences among the various breeds and among groups of breeds from different geographical areas. We also inferred that the genetic diversity in the Sardinian Giara and Sarcidano breeds is the result of recent evolution. We further demonstrated that the genetic system used is powerful of discerning past and present evolutionary patterns.

As to the question of horse domestication, we agree with other authors that horses are a notable exception to the theory that holds that domestication is the result of a very small number of independent, often geographically separated taming events, as observed for all domesticated species (Bruford et al., 2003). The abundance of very differentiated mtDNA lineages indicates that horse domestication probably involved a large number of wild captures. Our analysis support the hypothesis that the area of horse domestication was originally restricted and then gave rise to the high number of present-day horse mitochondrial lineages (Jansen et al., 2002; Forster et al., 2012); however, the subsequent recruitment of local mares from wild horse populations into domesticated herds is less apparent. According to our results, multiple radiation events of lineages from the original place of wild capture better explain the genetic structure of today's domestic horses.

\section{ACKNOWLEDGMENTS}

We thank Barbara Wilkens, Marco Apollonio, and Ercole Contu for useful discussions and helpful comments and breed owners for providing sample collections. Research supported by MURST ex60\% and the "Fondazione Banco di Sardegna" to L. Morelli and P. Francalacci. A. Useli was supported by the Autonomous Region of Sardinia and by the Programma Operativo Fondo Sociale Europeo 2007-2013.

\section{Supplementary material}

\section{REFERENCES}

Achilli A, Olivieri A, Soares P, Lancioni H, et al. (2012). Mitochondrial genomes from modern horses reveal the major haplogroups that underwent domestication. Proc. Natl. Acad. Sci. U. S. A. 109: 2449-2454.

Bandelt HJ, Forster P and Rohl A (1999). Median-joining networks for inferring intraspecific phylogenies. Mol. Biol. Evol. 16: 37-48.

Bower MA, Campana MG, Whitten M, Edwards CJ, et al. (2011). The cosmopolitan maternal heritage of the Thoroughbred racehorse breed shows a significant contribution from British and Irish native mares. Biol. Lett. 7: 316-320.

Bowling AT, Del Valle A and Bowling M (2000). A pedigree-based study of mitochondrial D-loop DNA sequence variation among Arabian horses. Anim. Genet. 31: 1-7. 
Bruford MW, Bradley DG and Luikart G (2003). DNA markers reveal the complexity of livestock domestication. Nat. Rev. Genet. 4: 900-910.

Cetti F (1774). I Quadrupedi di Sardegna. In: Storia Naturale di Sardegna (2000). Ilisso Biblioteca Sarda, Nuoro.

Cieslak M, Pruvost M, Benecke N, Hofreiter M, et al. (2010). Origin and history of mitochondrial DNA lineages in domestic horses. PLoS One 5: e15311.

Cozzi MC, Strillacci MG, Valiati P, Bighignoli B, et al. (2004). Mitochondrial D-loop sequence variation among Italian horse breeds. Genet. Sel. Evol. 36: 663-672.

Excoffier L, Smouse PE and Quattro JM (1992). Analysis of molecular variance inferred from metric distances among DNA haplotypes: application to human mitochondrial DNA restriction data. Genetics 131: 479-491.

Excoffier L, Laval G and Schneider S (2005). Arlequin (version 3.0): an integrated software package for population genetics data analysis. Evol. Bioinform. Online 1: 47-50.

Forster P, Hurles ME, Jansen T, Levine M, et al. (2012). Origins of the domestic horse. Proc. Natl. Acad. Sci. U. S. A. 109: E3148.

Georgescu SE, Manea MA, Dudu A and Costache M (2011). Phylogenetic relationships of the Hucul horse from Romania inferred from mitochondrial D-loop variation. Genet. Mol. Res. 10: 4104-4113.

Goto H, Ryder OA, Fisher AR, Schultz B, et al. (2011). A massively parallel sequencing approach uncovers ancient origins and high genetic variability of endangered Przewalski's horses. Genome Biol. Evol. 3: 1096-1106.

Guastella AM, Zuccaro A, Criscione A, Marletta D, et al. (2011). Genetic analysis of Sicilian autochthonous horse breeds using nuclear and mitochondrial DNA markers. J. Hered. 102: 753-758.

Gratani L (1980). Cavallo della Giara. Istituto di Incremento Ippico della Sardegna. RAS, Cagliari.

Hall TA (1999). BioEdit: a user-friendly biological sequence alignment editor and analysis program for Windows 95/98/ NT. Nucleic Acids Symp. Ser. 41: 95-98.

Hill EW, Bradley DG, Al-Barody M, Ertugrul O, et al. (2002). History and integrity of thoroughbred dam lines revealed in equine mtDNA variation. Anim. Genet. 33: 287-294.

Ishida N, Hasegawa T, Takeda K, Sakagami M, et al. (1994). Polymorphic sequence in the D-loop region of equine mitochondrial DNA. Anim. Genet. 25: 215-221.

Jansen T, Forster P, Levine MA, Oelke H, et al. (2002). Mitochondrial DNA and the origins of the domestic horse. Proc. Natl. Acad. Sci. U. S. A. 99: 10905-10910.

Jiang Q, Wei Y, Huang Y, Jiang H, et al. (2011). The complete mitochondrial genome and phylogenetic analysis of the Debao pony (Equus caballus). Mol. Biol. Rep. 38: 593-599.

Kakoi H, Tozaki T and Gawahara H (2007). Molecular analysis using mitochondrial DNA and microsatellites to infer the formation process of Japanese native horse populations. Biochem. Genet. 45: 375-395.

Kavar T and Dovc P (2008). Domestication of the horse: Genetic relationships between domestic and wild horses. Livest. Sci. 116: 1-14.

Lei CZ, Su R, Bower MA, Edwards CJ, et al. (2009). Multiple maternal origins of native modern and ancient horse populations in China. Anim. Genet. 40: 933-944.

Lippold S, Matzke NJ, Reissmann M and Hofreiter M (2011). Whole mitochondrial genome sequencing of domestic horses reveals incorporation of extensive wild horse diversity during domestication. BMC Evol. Biol. 11: 328.

Luís C, Bastos-Silveira C, Cothran EG and Oom MM (2006a). Iberian origins of New World horse breeds. J. Hered. 97 : 107-113.

Luís C, Bastos-Silveira C, Costa-Ferreira J, Cothran EG, et al. (2006b). A lost Sorraia maternal lineage found in the Lusitano horse breed. J. Anim. Breed. Genet. 123: 399-402.

McGahern AM, Edwards CJ, Bower MA, Heffernan A, et al. (2006a). Mitochondrial DNA sequence diversity in extant Irish horse populations and in ancient horses. Anim. Genet. 37: 498-502.

McGahern A, Bower MA, Edwards CJ, Brophy PO, et al. (2006b). Evidence for biogeographic patterning of mitochondrial DNA sequences in Eastern horse populations. Anim. Genet. 37: 494-497.

Mirol PM, Peral GP, Vega-Pla JL and Dulout FN (2002). Phylogenetic relationships of Argentinean Creole horses and other South American and Spanish breeds inferred from mitochondrial DNA sequences. Anim. Genet. 33: 356-363.

Nei M (1987). Molecular Evolutionary Genetics. Columbia University Press, New York.

Outram AK, Stear NA, Bendrey R, Olsen S, et al. (2009). The earliest horse harnessing and milking. Science 323: 1332-1335.

Royo LJ, Alvarez I, Beja-Pereira A, Molina A, et al. (2005). The origins of Iberian horses assessed via mitochondrial DNA. J. Hered. 96: 663-669.

Tajima F (1983). Evolutionary relationship of DNA sequences in finite populations. Genetics 105: 437-460.

Tajima F (1993). Measurement of DNA Polymorphism. In: Mechanisms of Molecular Evolution. Introduction to Molecular Paleopopulation Biology (Takahata N and Clark AG, eds.). Japan Scientific Societies Press, Sinauer Associates, Inc., Tokyo, 37-59. 
Weir BS (1996). The second National Research Council report on forensic DNA evidence. Am. J. Hum. Genet. 59: 497-500.

Xu S, Luosang J, Hua S, He J, et al. (2007). High altitude adaptation and phylogenetic analysis of Tibetan horse based on the mitochondrial genome. J. Genet. Genomics 34: 720-729.

$\mathrm{Xu}$ X and Arnason U (1994). The complete mitochondrial DNA sequence of the horse, Equus caballus: extensive heteroplasmy of the control region. Gene 148: 357-362.

Yang YH, Kim KI, Cothran EG and Flannery AR (2002). Genetic diversity of Cheju horses (Equus caballus) determined by using mitochondrial DNA D-loop polymorphism. Biochem. Genet. 40: 175-186.

Zuccaro A, Bordonaro S, Longeri M, Cozzi MC, et al. (2009). Mitochondrial DNA control region variation in Sanfratellano horse and two other Sicilian autochthonous breeds. Ital. J. Anim. Sci. 8: 180-182. 